\title{
An Integrated Bremsstrahlung Safety Shutter and Collimator Designed for the APS Front End Operating in the Top-up Mode
}

\section{Shu, T. Sanchez, and T. Kuzay}

\section{DISCLAIMER}

This report was prepared as an account of work sponsored by an agency of the United States Government. Neither the United States Government nor any agency thereof, nor any of their employees, makes any warranty, express or implied, or assumes any legal liability or responsibility for the accuracy, completeness, or usefulness of any information, apparatus, product, or process disclosed, or represents that its use would not infringe privately owned rights. Reference herein to any specific commercial product, process, or service by trade name, trademark, manufacturer, or otherwise does not necessarily constitute or imply its endorsement, recommendation, or favoring by the United States Government or any agency thereof. The views and opinions of authors expressed herein do not necessarily state or reflect those of the United States Government or any agency thereof.

\section{April 14, 1992}

\section{Experimental Facilities Division Advanced Photon Source Argonne National Laboratory}




\section{DISCLAIMER}

Portions of this document may be illegible in electronic image products. Images are produced from the best available original document. 


\title{
An Integrated Bremsstrahlung Safety Shutter and Collimator Designed for the APS Front End Operating in the Top-up Mode
}

\author{
Deming Shu, Tom Sanchez, and Tunch Kuzay \\ Advanced Photon Source, XFD \\ Argonne National Laboratory \\ Argonne, IL 60439
}

1. Introduction

The Bremsstrahlung safety shutter is an important device for synchrotron radiation facility personal safety. The APS front ends have double redundant safety shutter assemblies (as per PSAR requirements) that are located about $22.6 \mathrm{~m}$ from the source, just upstream of the ratchet wall, as shown in Fig. 1 [1]. These assemblies are needed to guard against an accidental positron beam loss during injection and normal operation, which then can result in high energy Bremsstrahlung radiation being directed down the front end into the First Optics Enclosure (FOE) and the experimental station.

In the APS top-up mode of operation [2], the positron injection will be continued during the normal operation. Therefore, it is necessary to have special Bremsstrahlung shielding to protect the downstream experimental area. There are many ways to do this, but the most economical way is to design a special long Bremsstrahlung collimator in the front-end area. The better the collimation in the front end, the less the shielding material needed in the beamline.

The major difficulty in designing the front-end special Bremsstrahlung collimator is the space problem. In the APS, the total length available for the APS ID front end is only about $7.6 \mathrm{~m}$; there is no extra space for additional collimators. To solve this problem, we propose here a novel integrated design that will provide the functions of both a Bremsstrahlung collimator and a safety shutter.

\section{The traditional design}

The traditional safety shutter is a high-Z-metal-based block operated by a pneumatic actuator, which is equipped with limit switches and is tied to the safety interlock system. The block length in the beam direction is determined by the storage ring Bremsstrahlung dose level.

In addition to the safety shutters, there are two or more Bremsstrahlung collimator on the beam axes as shown in Fig. 2 .

As a preliminary design for the APS front end, Fig. 3 shows the vertical Bremsstrahlung ray tracing result, which uses $20.85 \mathrm{~mm}$ as the maximum source offset (the wall of the storage ring vacuum chamber). The horizontal 
Bremsstrahlung shielding diagram is shown in Fig. 4. This design is good enough for traditional operation of synchrotron radiation facilities, which means that the safety shutter must be closed during the storage ring injection period.

3. The novel integral safety shutter/collimator design

To provide the best Bremsstrahlung shielding in the limited space available, we developed a new safety shutter that is adapted from a Bremsstrahlung shutter designed by the ESRF $[3,4]$. The ESRF safety shutter consists of two blocks, a movable top block and a bottom block fixed to the vacuum chamber. To avoid radiation leakage from the edge between these blocks when the top one is closed, a plug structure was designed. We call it the "1-D plug" as shown in Fig. 5. Using this structure results in a reduction of the actuator working stroke and loading rate.

We have improved this "1-D plug" by adding horizontal "plug" structures on both sides, and it is now referred to as the "2-D plug." Fig. 6 shows the design in a step-by-step fashion: fig. 6(a) shows that the new "plug" length is reasonable and limited, fig. $6(\mathrm{~b})$ shows the added horizontal plugs, and fig. $6(\mathrm{c})$ shows the final structure, which provides a rectangular Bremsstrahlung shielding collimator aperture.

The new combined safety shutter/collimator uses the same space as the original design (fig. 7), but, significant shielding improvement has been obtained (figs. 8 and 9).

4. Conclusion

A novel combined safety shutter/collimator design provides the functions of both a safety shutter and a collimator in a single device. As in our previous design, the total length of the on-beam-axis shielding is $600 \mathrm{~mm}$ (doubly redundant, $300 \mathrm{~mm}$ each). The top block vertical travel distance is $30 \mathrm{~mm}$. As such, when the shutter is open, the effective collimator shielding aperture is $72 \mathrm{~mm}(\mathrm{H}) \times 20 \mathrm{~mm}(\mathrm{~V})$. The new design not only reduces the aperture size from $76 \mathrm{~mm} \times 24 \mathrm{~mm}$ to $72 \mathrm{~mm} \times 20 \mathrm{~mm}$, but also provides extra long collimation, which will reduce the unshielded angle both horizontally and vertically. This should simplify the shielding design of the FOE and the experimental hutches for the APS top-up mode.

Investigation is also underway to find high- $\mathrm{Z}$ metallic alloys suitable for machining or for forming the components of the safety shutter/collimator. Some candidate materials have already been identified.

Acknowledgement: This work supported by the U. S. Department of Energy, Experimental Facilities, Advanced Photon Source under Contract W-31-109-Eng38. 
Figure Captions

1. Top view of the APS ID front end

2. Side view of the APS ID front end

3. Vertical Bremsstrahlung ray tracing result for APS ID front end preliminary design

4. Horizontal Bremsstrahlung shielding diagram for APS ID front end preliminary design

5. ESRF safety shutter "1-D plug" structure

6a. APS novel "2-D plug" structure design (step one)

6b. APS novel "2-D plug" structure design (step two)

6c. APS novel "2-D plug" structure design (final step for an integrated safety shutter/collimator

7. Side view of the APS integrated safety shutter

8. Vertical Bremsstrahlung ray tracing result for APS front end using new safety shutter/collimator

9. Horizontal Bremsstrahlung shielding diagram for APS front end using new safety shutter/collimator 


\section{References}

[1] D. Shu, J. Barraza, T. Sanchez, R. W. Nielsen, J. T. Collins, and T. M. Kuzay, "Front End Designs for the $7 \mathrm{GeV}$ Advanced Photon Source," 7th Nat. Conf. on SRI, Baton Rouge, LA, (Oct. 28-31, 1991), to be published in Nucl. Instr. and Meth., 1992.

[2] J. Galayda, (private communication)

[3] T. M. Kuzay, ESRF Trip Report, March 1992

[4] Elke Bräuer, "Radiation Protection Study for Personal Safety Shutters at the ESRF," RP/89-92, Nov., 1989. 


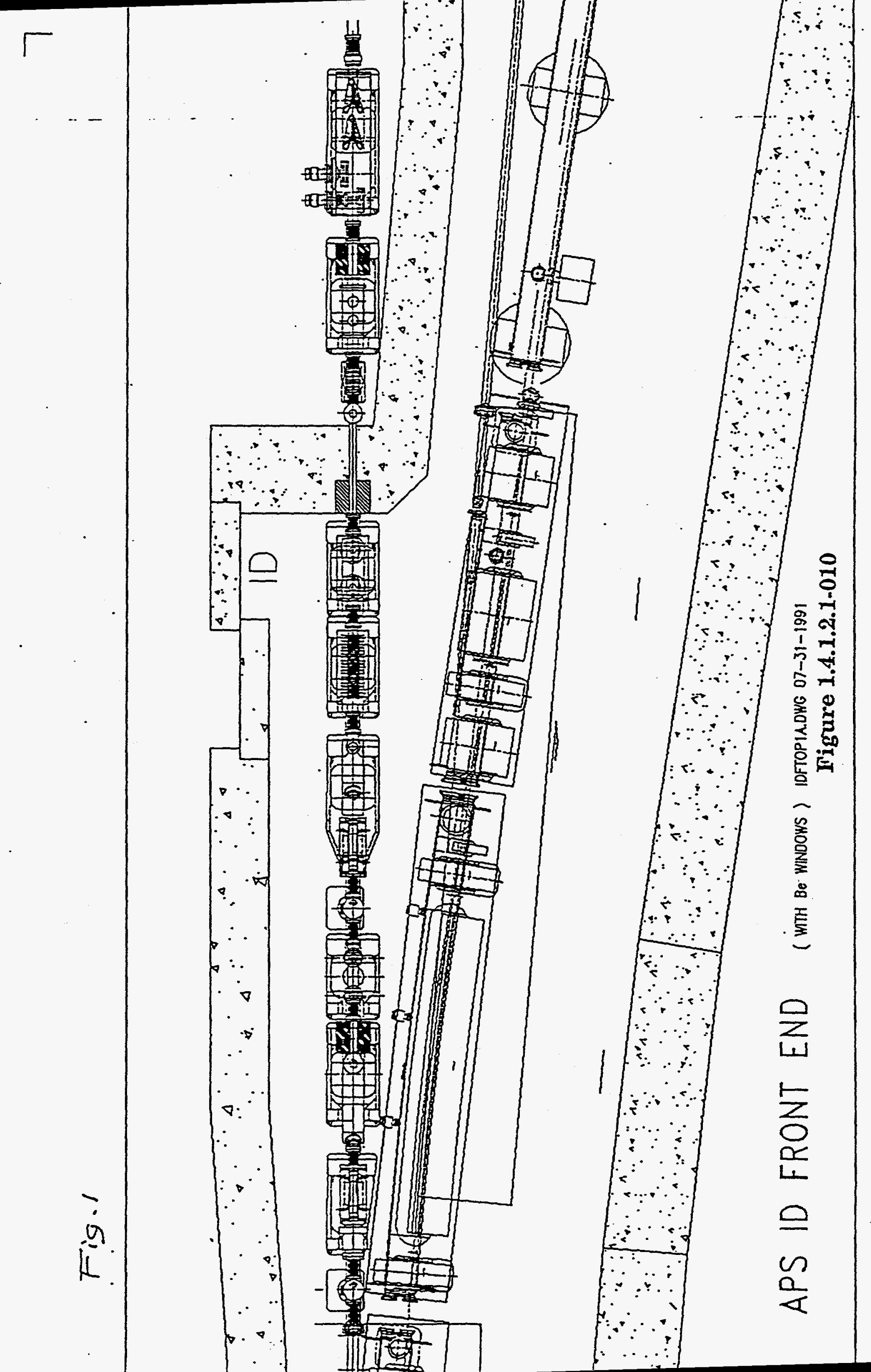




\section{VERTICAL BREMSSTRAHLUNG RAY TRACING}

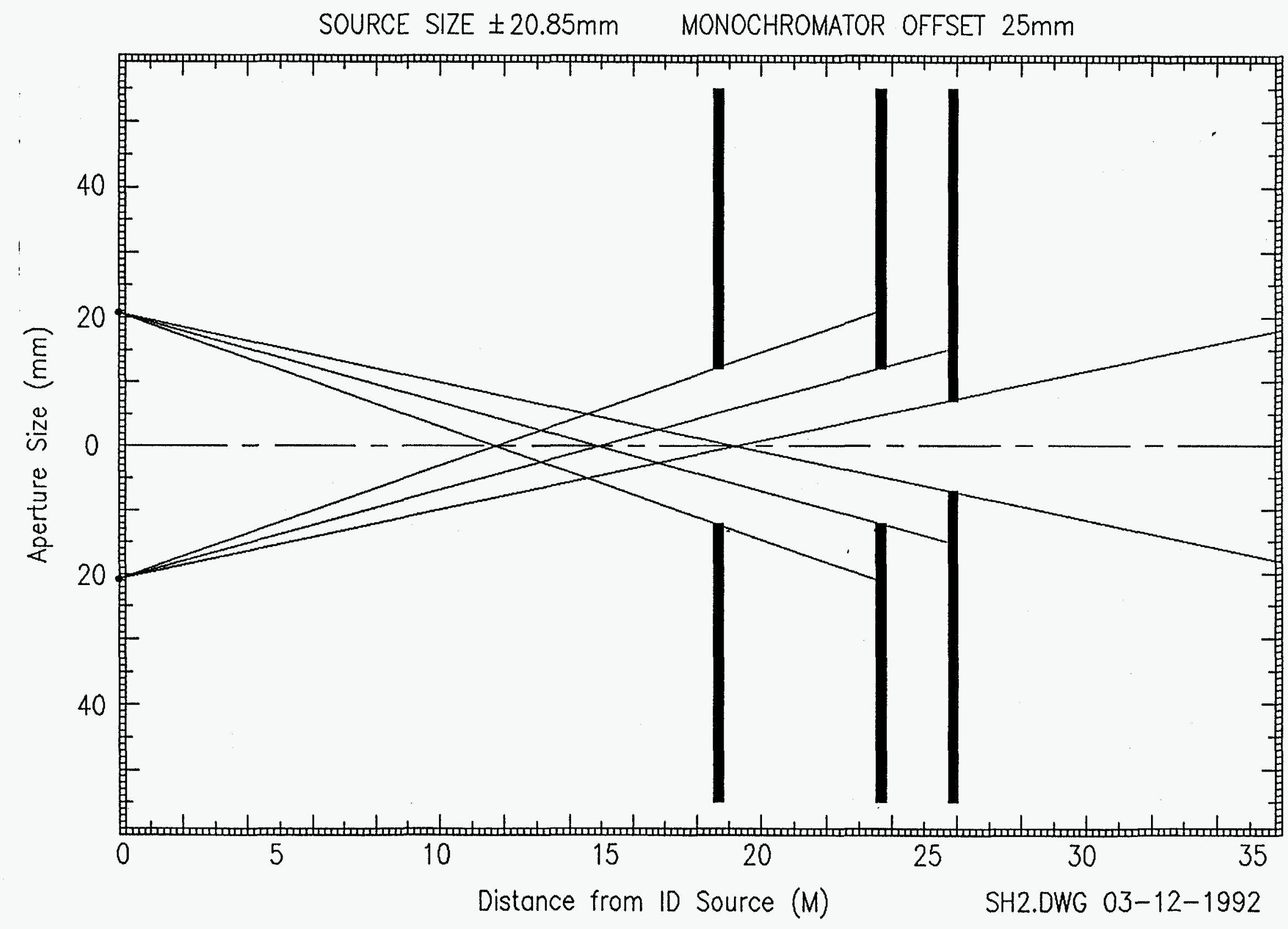

Fig. 3 


\section{HORIZONTAL BREMSSTRAHLUNG SHIELDING}

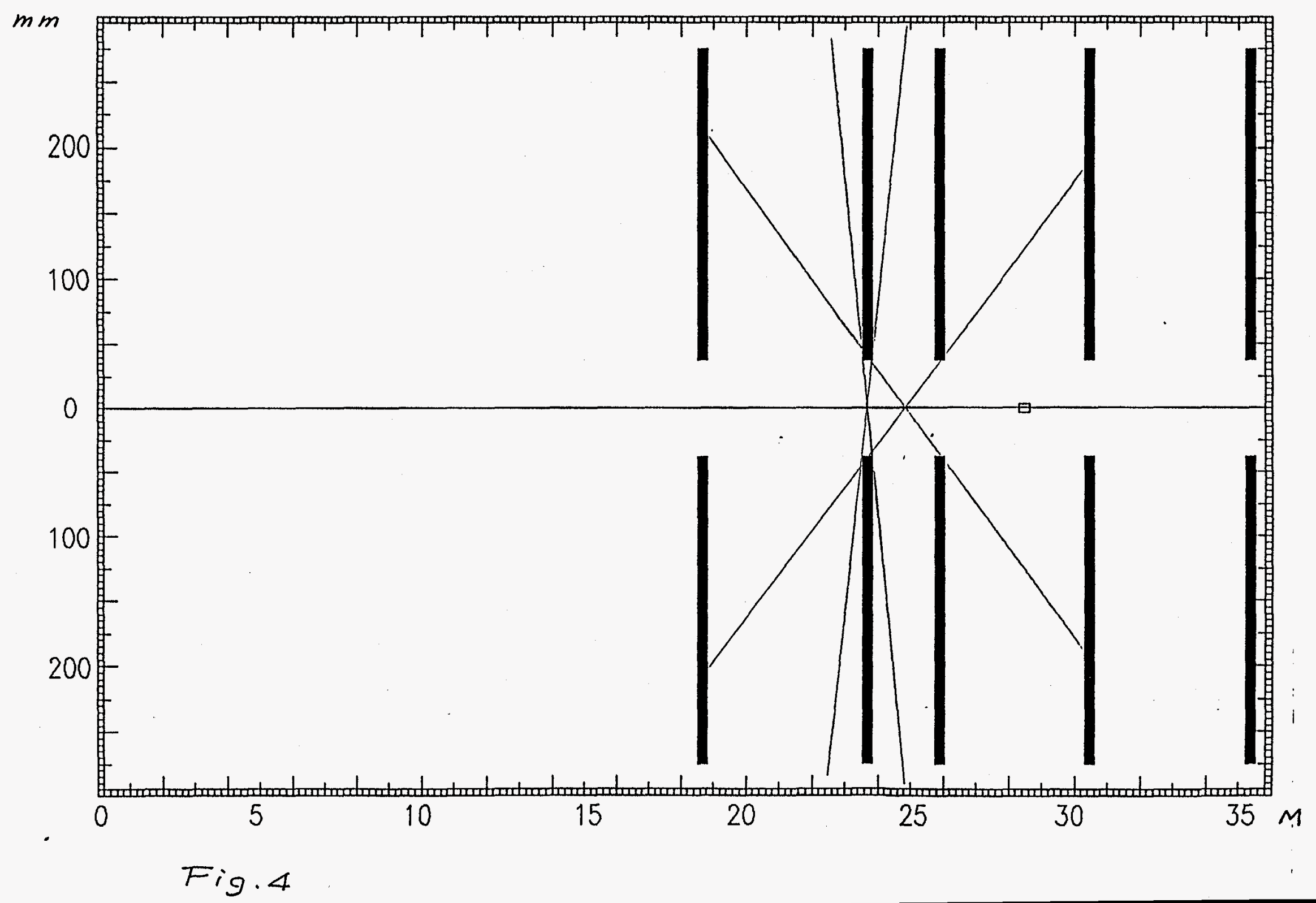



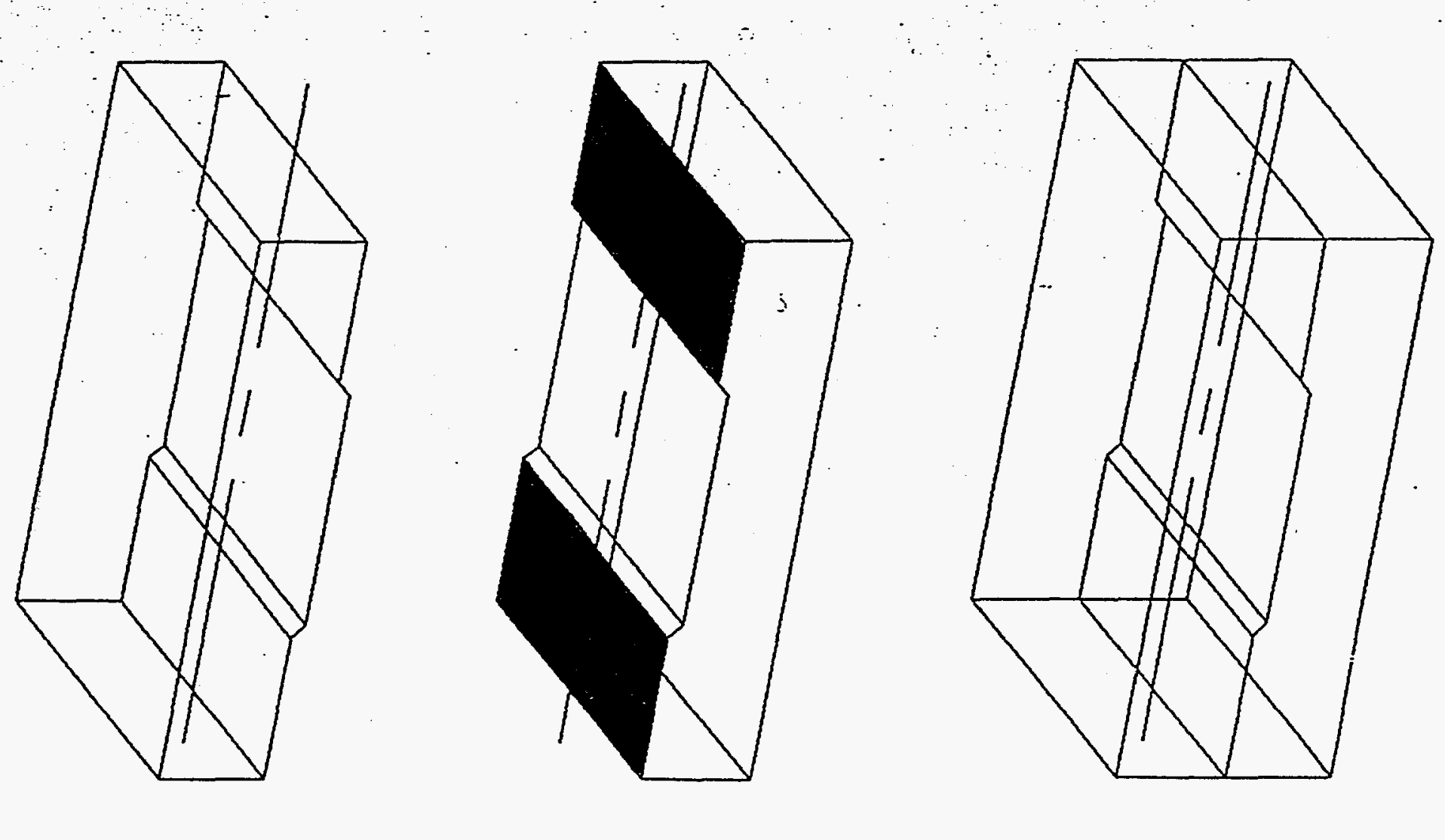

$\dot{b}$
$\dot{1}$ 

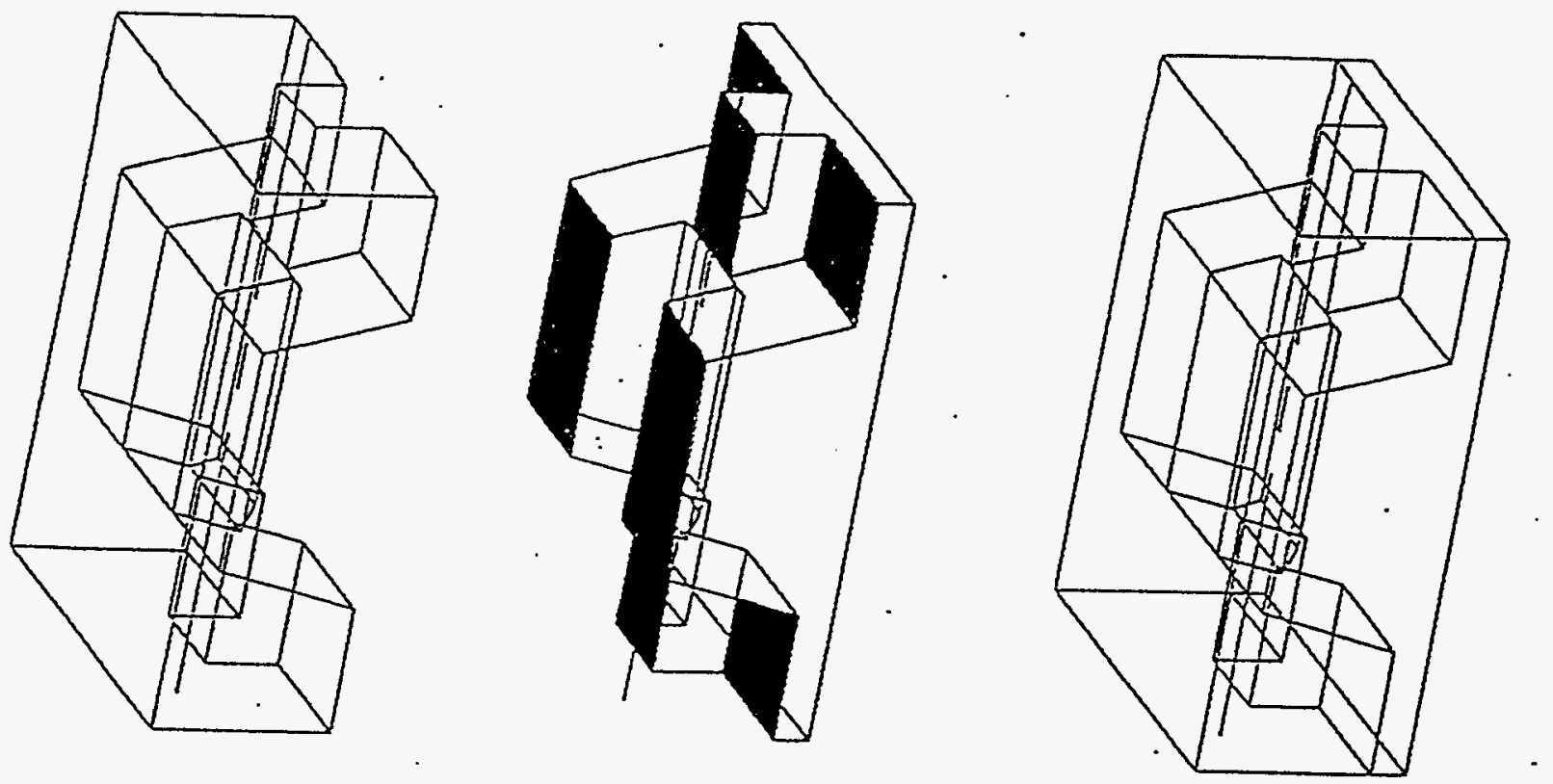

$u$
$u$
$\ddot{1}$
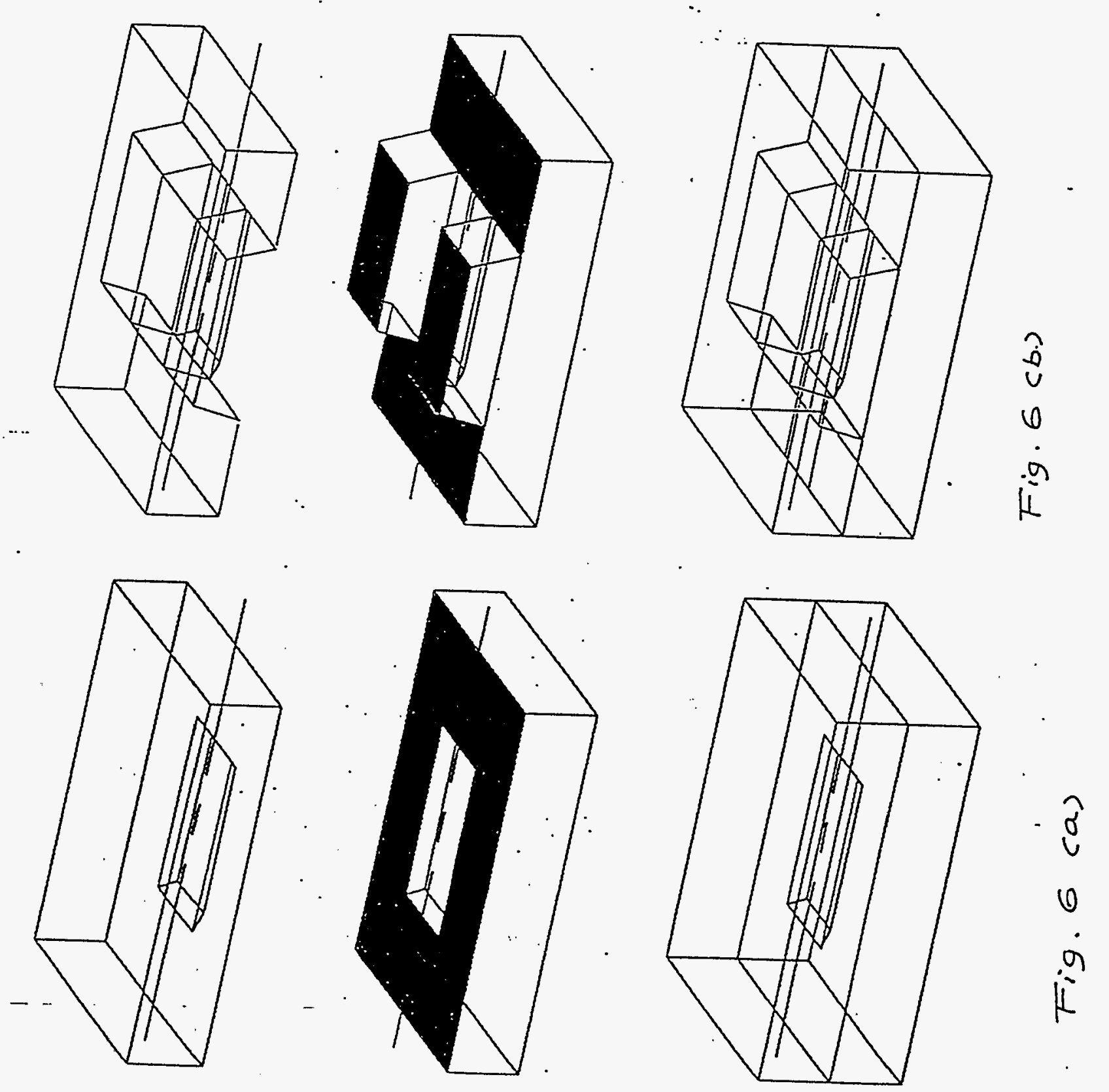


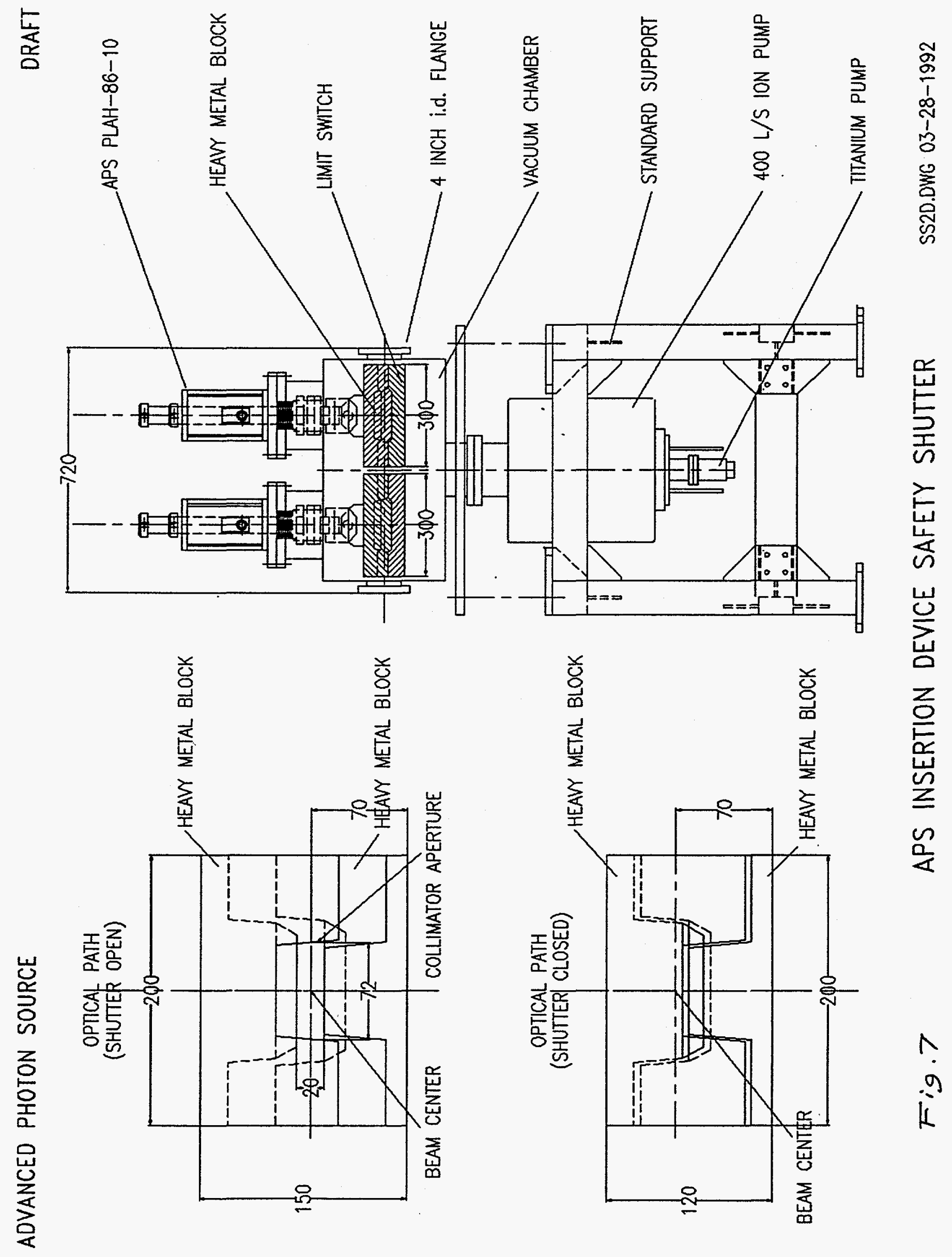




\section{VERTICAL BREMSSTRAHLUNG RAY TRACING}

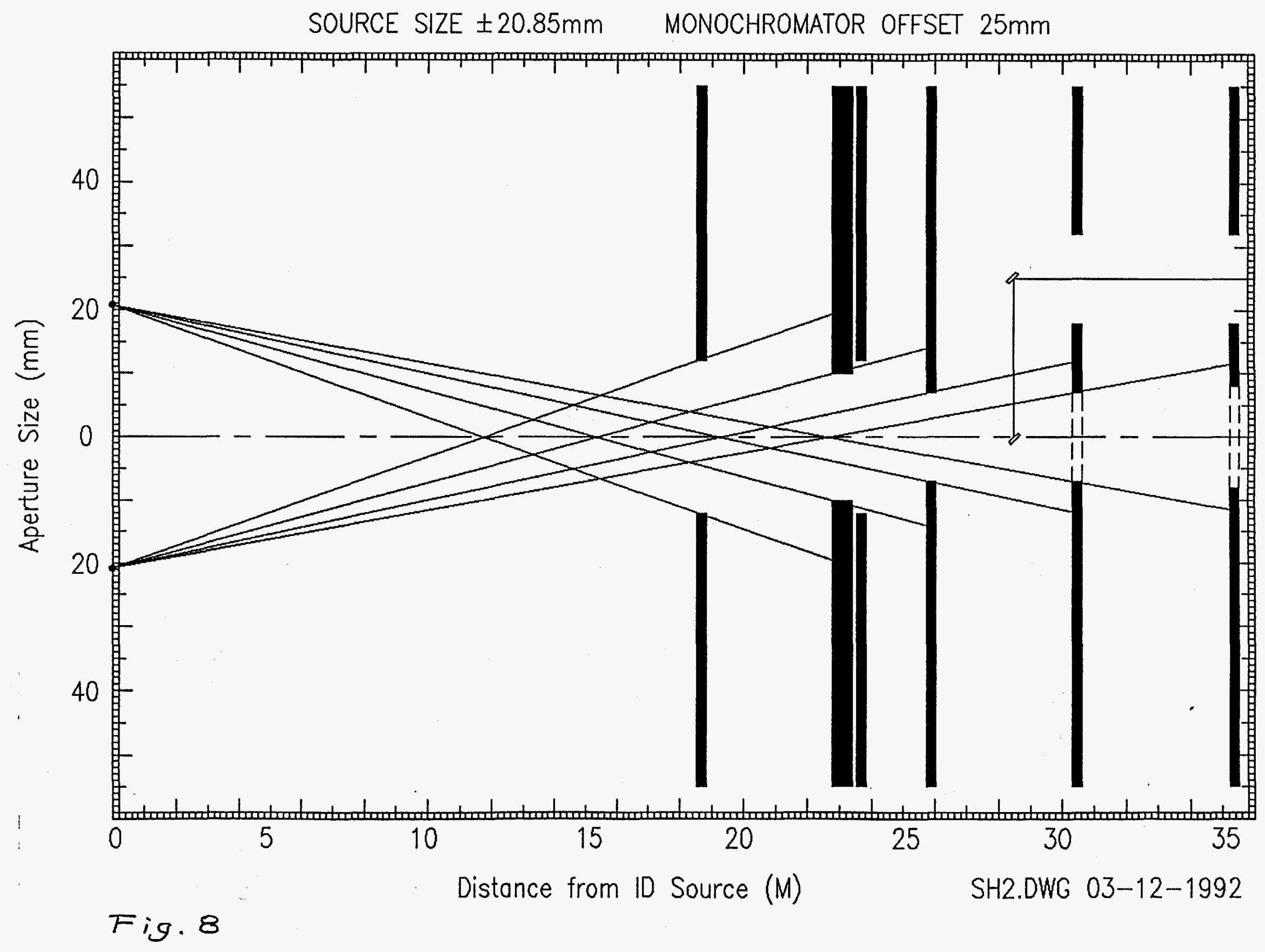




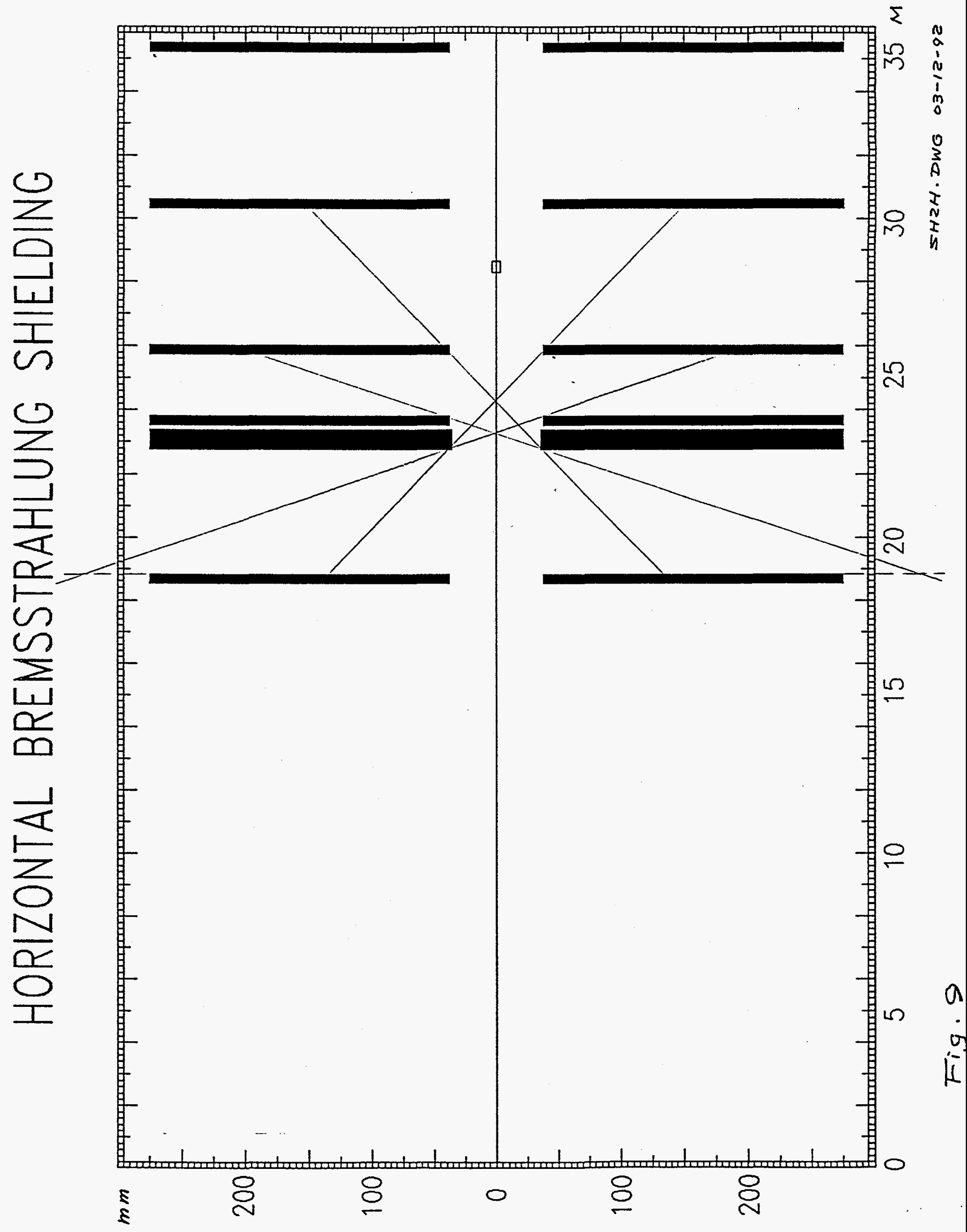

